\title{
Comparative expression analysis of rpf-like genes of Mycobacterium tuberculosis H37Rv under different physiological stress and growth conditions
}

Correspondence

Ranjana Srivastava

drranjana@yahoo.com

Received 25 December 2009

Revised 26 May 2010

Accepted 27 May 2010

\author{
Ravi Kr. Gupta, Brahm S. Srivastava and Ranjana Srivastava \\ Microbiology Division, Central Drug Research Institute, CSIR, Lucknow 226001, India
}

\section{INTRODUCTION}

Persistence and reactivation play significant roles in the pathogenesis of Mycobacterium tuberculosis. Only a proportion of persons infected with $M$. tuberculosis develop active tuberculosis, while the majority of them harbour the bacilli for an extended period of time in the form of latent infection without producing clinical symptoms. Approximately one-third of the world's population is infected with latent $M$. tuberculosis, and run the risk of reactivation, causing active disease (WHO, 2010; GeddeDahl, 1952). Hence, an understanding of mycobacterial persistence and reactivation is crucial for effective control of the disease.

The translation from replicating to a dormant state and then to reactivation remains an enigma. In recent years, a class of protein has been identified that act like growth factors for dormant mycobacteria. The protein known as resuscitation-promoting factor was originally identified in Micrococcus luteus as a $\sim 16-17 \mathrm{kDa}$ protein that is secreted by actively growing bacteria. The protein in picomolar concentrations is able to resuscitate dormant Micrococcus luteus or mycobacteria generated by prolonged incubation

Abbreviations: NC, non-culturable; NCC non-culturable cells.

A set of supplementary methods, describing the protocol for cDNA synthesis, a supplementary figure, showing amplification efficiency for each primer set, and a supplementary table, showing the data used to calculate the normalized ratios, are available with the online version of this paper. in spent culture medium (Mukamolova et al., 1998a, b; Shleeva et al., 2002). M. tuberculosis contains five Rpf homologues which share sequence as well as functional homology with Rpf of Micrococcus luteus in their capacity to resuscitate dormant Mycobacterium bovis BCG or M. tuberculosis in vitro (Mukamolova et al., 2002). The five $r p f$-like genes of $M$. tuberculosis $\mathrm{H} 37 \mathrm{Rv}$ are distributed throughout the chromosome and are designated $r p f A$ (Rv0867c), $r p f B$ (Rv1009), rpfC (Rv1884c), rpfD (Rv2389c) and $r p f E$ (Rv2450c) (http://genolist.pasteur.fr/tuberculist/). The presence of five rpf-like genes in M. tuberculosis is intriguing, as all five genes are expressed in vitro and in vivo in the lungs of mice acutely infected with $M$. tuberculosis (Tufariello et al., 2004; Mukamolova et al., 2002; Downing et al., 2004). Transcripts for all the rpf-like genes are detectable at the earliest time points, although relative expression has been shown to differ at later time points during growth in culture (Tufariello et al., 2004; Mukamolova et al., 2002). Strains harbouring deletions of individual $r p f$-like genes from $M$. tuberculosis do not show significant alteration of growth in vitro and in vivo (Tufariello et al., 2004; Downing et al., 2004). Earlier studies have confirmed that $r p f A-E$ are collectively dispensable for growth of $M$. tuberculosis in vitro and in vivo and suggest a functional hierarchy within this multigene family under different conditions (Kana et al., 2008). Deletion of individual $r p f B-E$ genes has been shown to be accompanied by upregulation of some or all of the remaining rpf-like genes (Downing et al., 2004), although later studies with multiple $r p f$ mutants have clearly shown 
that $r p f$-like genes do not compensate for the loss of other genes by transcriptional upregulation; instead they suggest that $r p f$-like genes are likely to be regulated by other distinct mechanisms (Downing et al., 2005; Kana et al., 2008). In this respect, it is worth noting that $r p f A$ has been shown to be regulated by cAMP receptor protein (Rickman et al., 2005), while $r p f C$ is positively regulated by the sigma factor SigD (Raman et al., 2004). RpfB and RpfE have been shown to interact with mycobacterial endopeptidase RipA (Rpf-interacting protein), resulting in peptidoglycan hydrolysis. RipA does not interact with RpfA, C and D, adding to the complexity of Rpf function and regulation (Hett et al., 2007).

In this study, we have explored by real-time PCR the relative expression of all five $r p f$-like genes of $M$. tuberculosis $\mathrm{H} 37 \mathrm{Rv}$ during different growth stages, ranging from exponential phase to the non-culturable (NC) state and subsequent Rpf-mediated resuscitation. The relative expression profiling was further extended to three different physiological stress conditions; namely, nutrient starvation, hypoxia and acid stress.

\section{METHODS}

Bacterial strains and culture conditions. M. tuberculosis $\mathrm{H} 37 \mathrm{Rv}$ was grown in Sauton's medium containing albumin-dextrosecatalase (ADC; Becton Dickinson) and Tween $80(0.05 \%, \mathrm{v} / \mathrm{v})$ without shaking at $37{ }^{\circ} \mathrm{C}$. For the resuscitation of NC cells of $M$. tuberculosis, filter-sterilized supernatant of actively growing $M$. tuberculosis culture $\left(\mathrm{OD}_{600} 0.5\right)$ was used. Methylene blue $(1.5 \mu \mathrm{g}$ $\mathrm{ml}^{-1}$ ) was used as a redox indicator in hypoxia experiments.

Formation of non-culturable cells (NCC) and their resuscitation. The NC state was achieved as described by Shleeva et al. (2003). Briefly, NCC of M. tuberculosis were obtained by prolonged incubation of culture in Sauton's medium containing Tween 80 $(0.05 \%, \mathrm{v} / \mathrm{v})$ and $\mathrm{ADC}$ for 6 months at $37{ }^{\circ} \mathrm{C}$ (Shleeva et al., 2003; Salina et al., 2006). Samples were taken at regular intervals and passed through a 23-gauge syringe needle before plating to make the culture homogeneous. Plating was done on MB7H10 agar medium containing oleic acid-albumin-dextrose-catalase (OADC; Becton Dickinson). After 6 months of incubation, M. tuberculosis became $\mathrm{NC}$, as c.f.u. levels were less than 5 cells $\mathrm{ml}^{-1}$. Resuscitation of NCC was induced by cell-free culture supernatant of exponential phase $\left(\mathrm{OD}_{600}\right.$ 0.5) M. tuberculosis $\mathrm{H} 37 \mathrm{Rv}$ culture, as described by Shleeva et al. (2003). The cells were removed by centrifugation at $6000 \mathrm{~g}$ for $10 \mathrm{~min}$ and the supernatant was filter-sterilized with a $0.22 \mu \mathrm{m}$ poresize filter (Whatman) at $4{ }^{\circ} \mathrm{C}$ and used within $20 \mathrm{~min}$.

RNA isolation from different growth stages. An exponentialphase starter culture of $M$. tuberculosis $\mathrm{H} 37 \mathrm{Rv}$ was used to inoculate the working culture at an approximate density of $10^{6}$ c.f.u. $\mathrm{ml}^{-1}$ (based on the estimate that $\mathrm{OD}_{600} 1=5 \times 10^{8}$ c.f.u. $\mathrm{ml}^{-1}$ ) in Sauton's medium containing ADC and Tween 80 at $37{ }^{\circ} \mathrm{C}$ without shaking. RNA extraction was done at different growth stages such as early exponential phase $\left(\mathrm{OD}_{600} 0.2\right.$, 5-day-old culture), exponential phase $\left(\mathrm{OD}_{600}\right.$ 0.6, 3-week-old culture), stationary phase $\left(\mathrm{OD}_{600} 2.5,3\right.$ month-old culture), $\mathrm{NC}$ state $\left(\mathrm{OD}_{600} 4.5,6\right.$-month-old culture) and resuscitation phase $\left(\mathrm{OD}_{600} 0.2,3\right.$ days after resuscitation). From the various growth phases described above, $30 \mathrm{ml}$ culture was harvested in triplicate from three independent experiments. RNA isolation was done according to the kit protocol (RNeasy Mini kit, Qiagen) and quantified by Qubit fluorometer (Invitrogen).

Acid stress. M. tuberculosis $\mathrm{H} 37 \mathrm{Rv}$ culture was grown in $100 \mathrm{ml}$ Sauton's medium ( $\mathrm{pH} 7.2)$ containing Tween $80(0.05 \%$, v/v) at $37{ }^{\circ} \mathrm{C}$ without shaking. When the $\mathrm{OD}_{600}$ reached 0.6 , cells were divided into three $30 \mathrm{ml}$ aliquots, centrifuged at $6000 \mathrm{~g}$ for $10 \mathrm{~min}$ at room temperature, resuspended in $50 \mathrm{ml}$ Sauton's medium ( $\mathrm{pH} 4.5$, pH 5.5 or $\mathrm{pH} 7.2)$ containing Tween $80(0.05 \%$, v/v) and kept at $37{ }^{\circ} \mathrm{C}$ without shaking. After $24 \mathrm{~h}$ of acid shock, $30 \mathrm{ml}$ culture from each flask was pelleted. RNA isolated from the culture grown in Sauton's medium at $\mathrm{pH} 7.2$ was used as a control or positive calibrator for relative expression analysis. RNA isolation was done according to the kit protocol (RNeasy Mini kit, Qiagen) and quantified by Qubit fluorometer (Invitrogen). RNA was isolated from three independent experiments.

Nutrient starvation. An exponentially growing $M$. tuberculosis $\mathrm{H} 37 \mathrm{Rv}$ culture $\left(\mathrm{OD}_{600} 0.6\right)$ in Sauton's medium with Tween 80 $(0.05 \%, \mathrm{v} / \mathrm{v})$ was centrifuged at $6000 \mathrm{~g}$ for $10 \mathrm{~min}$ at room temperature. Cells were washed twice with PBS with Tween 80 $(0.05 \%, \mathrm{v} / \mathrm{v}) \mathrm{pH} 7.2$ and resuspended in $100 \mathrm{ml}$ PBS-Tween ( $\mathrm{pH}$ 7.2). The culture was incubated at $37{ }^{\circ} \mathrm{C}$ without shaking. Cells were harvested at 0,24 and $96 \mathrm{~h}$. Cells harvested at $0 \mathrm{~h}$ served as a control (Betts et al., 2002). RNA isolation was done by using the RNeasy Mini kit (Qiagen) and quantified by Qubit fluorometer (Invitrogen). The experiment was repeated three times with three independent experimental set-ups.

Hypoxia conditions. An aerobic exponentially growing culture of $M$. tuberculosis $\mathrm{H} 37 \mathrm{Rv}$ was diluted to $\mathrm{OD}_{600} 0.005$ in $\mathrm{MB} 7 \mathrm{H} 9$ medium containing ADC, Tween $80(0.05 \%, \mathrm{v} / \mathrm{v})$ and the redox dye methylene blue $\left(1.5 \mu \mathrm{g} \mathrm{ml}^{-1}\right)$. The culture was transferred to sealed rubbercapped tubes (50\% headspace ratio) and kept standing at $37{ }^{\circ} \mathrm{C}$. Anaerobiosis was monitored by decolorization of the redox indicator methylene blue (Boon et al., 2001). Complete decolorization of the dye was obtained after 25 days incubation at $37^{\circ} \mathrm{C}$. For control samples, tubes were not sealed and were kept at $37^{\circ} \mathrm{C}$ with periodic exposure to air by shaking for the same period of time. The cells were pelleted on the 26th day in triplicate, and RNA was isolated by using the RNeasy Mini kit (Qiagen) and quantified by Qubit fluorometer (Invitrogen).

cDNA synthesis. Each RNA sample was treated with RNase-free DNase I (Fermentas) and heat-inactivated according to the manufacturer's instructions. RNA integrity was checked by formaldehyde agarose gel electrophoresis. After staining with ethidium bromide, three sharp bands of 23S, $16 \mathrm{~S}$ and 5S rRNA were seen. DNA contamination was checked by (no reverse transcription) PCR for each RNA sample in a gradient cycler (Mastercycler gradient, Eppendorf) using a $16 \mathrm{~S}$ rRNA primer. No amplification was seen after 30 cycles of amplification. PCR cycling parameters were: initial denaturation at $95{ }^{\circ} \mathrm{C}$ for $5 \mathrm{~min}$, denaturation at $94{ }^{\circ} \mathrm{C}$ for $1 \mathrm{~min}$, annealing at $60{ }^{\circ} \mathrm{C}$ for $30 \mathrm{~s}$, extension at $72{ }^{\circ} \mathrm{C}$ for $30 \mathrm{~s}$ for 30 cycles, followed by a final extension of $10 \mathrm{~min}$ at $70{ }^{\circ} \mathrm{C}$. PCR was performed in a $20 \mu \mathrm{l}$ reaction mix containing $1.25 \mathrm{U}$ DreamTaq DNA polymerase (Fermentas), 16S rRNA primers $(0.2 \mu \mathrm{M}$ each), RNA template $\left(100 \mathrm{ng}\right.$ ), $\mathrm{MgCl}_{2}$ (final concentration $2.0 \mathrm{mM}$ ) and dNTPs (final concentration $0.2 \mathrm{mM}$ ). PCR products were electrophoresed in a $2.5 \%$ agarose gel and visualized by ethidium bromide staining.

A 300-400 ng RNA sample was used for cDNA synthesis using random hexamer primers with the RevertAid First Strand H Minus cDNA synthesis kit (Fermentas). A detailed protocol for cDNA synthesis is available with the online version of this paper. Real-time quantitative PCR was performed in a LightCycler 480II instrument (Roche) using a LightCycler 480 SYBR Green I Master kit (Roche). 
Primers were designed using DNASTAR primer design software and purchased from Sigma-Aldrich. All primer sets were optimized for annealing temperature and concentration to ensure that only a single product of the correct size would be amplified. The optimum annealing temperature and primer concentration were found to be $68{ }^{\circ} \mathrm{C}$ and $0.5 \mu \mathrm{M}$.

PCR efficiency and real-time PCR. Amplification efficiency for each primer set was calculated by serially diluting exponential-phase cDNA template. Efficiency values were calculated by the software in LightCycler $480 \mathrm{II}$ and were in the optimum range. Efficiency values for each primer set are given in Table 1 and Supplementary Fig. S1, and showed high linearity in the investigated range of $0.1-100 \mathrm{ng}$ cDNA.

For LightCycler reactions, a master mix of the following components was prepared: $7.0 \mu \mathrm{l} \mathrm{PCR-grade} \mathrm{water,} 1.0 \mu \mathrm{l}(0.5 \mu \mathrm{M})$ forward primer, $1.0 \mu \mathrm{l}(0.5 \mu \mathrm{M})$ reverse primer, $10 \mu \mathrm{l} 2 \times$ Master Mix, $1.0 \mu \mathrm{l}$ cDNA (50-100 ng). A multiwell plate was sealed with sealing foil, centrifuged at $1500 \mathrm{~g}$ for $1 \mathrm{~min}$ and loaded into the LightCycler 480II instrument. Amplification was performed in triplicate wells for each sample analysed; a control reaction with no template (water) was run with all reactions. In each set of reactions, 16S rRNA was used as a reference gene for normalization of cDNA amount. Real-time PCR analysis was performed using the following optimized assay conditions: denaturation program $\left(95^{\circ} \mathrm{C}\right.$ for $\left.10 \mathrm{~min}\right)$; amplification and quantification program repeated for 45 cycles $\left(95{ }^{\circ} \mathrm{C}\right.$ for $10 \mathrm{~s}, 68{ }^{\circ} \mathrm{C}$ for $20 \mathrm{~s}, 72{ }^{\circ} \mathrm{C}$ for $30 \mathrm{~s}$ with a single fluorescence measurement); melting curve program $\left(95{ }^{\circ} \mathrm{C}\right.$ for $10 \mathrm{~s}, 70{ }^{\circ} \mathrm{C}$ for 1 min with continuous fluorescence measurement at $97^{\circ} \mathrm{C}$ ); and finally a cooling step at $40{ }^{\circ} \mathrm{C}$ for $30 \mathrm{~s}$.

Relative quantification analysis was done using an efficiency-calibrated model (Pfaffl., 2001), and the normalized ratio was calculated as:

Ratio $=\frac{\left(E_{\text {target }}\right)^{\Delta \mathrm{CP}_{\text {target }}}}{\left(E_{\text {reference }}\right)^{\Delta \mathrm{CP}_{\text {reference }}}}$

Where $\mathrm{CP}=$ crossing point, $\Delta \mathrm{CP}_{\text {target }}=\mathrm{CP}_{\text {control }}-\mathrm{CP}_{\text {sample }}, \Delta \mathrm{CP}_{\text {reference }}=$ $\mathrm{CP}_{\text {control }}-\mathrm{CP}_{\text {sample, }}, E_{\text {target }}=$ amplification efficiency of target gene, and $E_{\text {reference }}=$ amplification efficiency of reference gene.
Melting curve analysis was performed after each run in a LightCycler $480 \mathrm{II}$ instrument to confirm the specificity of the primers.

Statistical analysis. $\mathrm{CP}$ values for each run were used to calculate mean $\mathrm{CP}$ with SD and SE. The normalized ratio was calculated using the efficiency-calibrated model (see Supplementary Table S1). The relative expression ratio was calculated from triplicate normalized ratios for each gene with SD (Table 2). Student's $t$ test was performed to determine the significance of the relative expression ratios. $P<0.05$ was considered significant $\left(^{*}\right), P<0.01$ was considered highly significant ${ }^{* *}$ ) and $P>0.05$ was considered not significant.

\section{RESULTS}

\section{rpf-like genes are differentially expressed during growth of the cell}

The relative expression of all five $r p f$ genes $(r p f A-E)$ was followed in exponential, stationary, NC and resuscitation phases. All five $r p f s(r p f A-E)$ were expressed in the early exponential phase (Tufariello et al., 2004; this study), and hence RNA from this stage was taken as a positive calibrator for quantification of relative expression in different growth stages (Fig. 1). $r p f B, r p f C$ and $r p f E$ had a higher expression ratio in exponential phase; the relative expression of $r p f B$ and $r p f E$ was reduced in stationary phase. The expression ratio of $r p f D$ was lower in exponential phase but higher in the stationary and $\mathrm{NC}$ phases. However, only $r p f C$ was found to be upregulated consistently in the exponential to stationary and $\mathrm{NC}$ phases. The relative expression of rpfA remained lower in exponential and NC phase but higher in resuscitation phase. Thus, from the data it appears that $r p f C$ and $r p f D$ have a role in stationary phase adaptation and persistence, while $r p f B$ and $r p f E$ may be required in exponential phase. Interestingly, in resuscitation phase, the relative expression

Table 1. Primer sequences with amplicon size and melting temperature

Amplification efficiency for each primer set was calculated using a LightCycler 480II instrument by serially diluting exponential-phase cDNA template in the investigated range of $0.1-100 \mathrm{ng}$ cDNA with high linearity.

\begin{tabular}{|c|c|c|c|c|}
\hline Gene & Forward and reverse primer sequences $\left(5^{\prime}-3^{\prime}\right)$ & Amplicon size & $T_{\mathrm{m}}^{*}$ & Amplification efficiency \\
\hline \multirow[t]{2}{*}{$r p f A$} & ggtgtgcggccgcgggttatcg & $179 \mathrm{bp}$ & $69.57{ }^{\circ} \mathrm{C}$ & 2.042 \\
\hline & ccagcggtgcgggcaggtcgttag & & $71.25{ }^{\circ} \mathrm{C}$ & \\
\hline \multirow[t]{2}{*}{$r p f B$} & cgacgctaagcaggtgtggacgac & $221 \mathrm{bp}$ & $67.84{ }^{\circ} \mathrm{C}$ & 1.909 \\
\hline & cactcagcagcccegcgacattgg & & $69.55^{\circ} \mathrm{C}$ & \\
\hline \multirow[t]{2}{*}{$r p f C$} & gtcacggcatccatgtcgctctcc & $154 \mathrm{bp}$ & $67.84{ }^{\circ} \mathrm{C}$ & 2.015 \\
\hline & cccaggtggccggcttgaact & & $65.68{ }^{\circ} \mathrm{C}$ & \\
\hline \multirow[t]{2}{*}{$r p f D$} & gccgcgagtccccagcaacagat & $144 \mathrm{bp}$ & $67.77^{\circ} \mathrm{C}$ & 2.152 \\
\hline & ggccgcgaggaacgtcaggatg & & $67.70{ }^{\circ} \mathrm{C}$ & \\
\hline \multirow[t]{2}{*}{$r p f E$} & ccagccggtatcgccaatg & $269 \mathrm{bp}$ & $60.98{ }^{\circ} \mathrm{C}$ & 1.855 \\
\hline & ccaccggactcgcactg & & $60.00{ }^{\circ} \mathrm{C}$ & \\
\hline \multirow[t]{2}{*}{ 16S rRNA } & tcccgggccttgtacaca & $75 \mathrm{bp}$ & $67.70{ }^{\circ} \mathrm{C}$ & 1.935 \\
\hline & ccactggcttcgggtgtta & & $66.00{ }^{\circ} \mathrm{C}$ & \\
\hline
\end{tabular}

${ }^{\star}$ Melting temperature. 
Table 2. Relative expression of all five rpf-like genes of $M$. tuberculosis H37Rv during different growth stages and under physiological stress conditions

The mean expression ratio and SD were calculated from the normalized ratio of three independent experiments. A.S., acid stress; N.S., nutrient starvation.

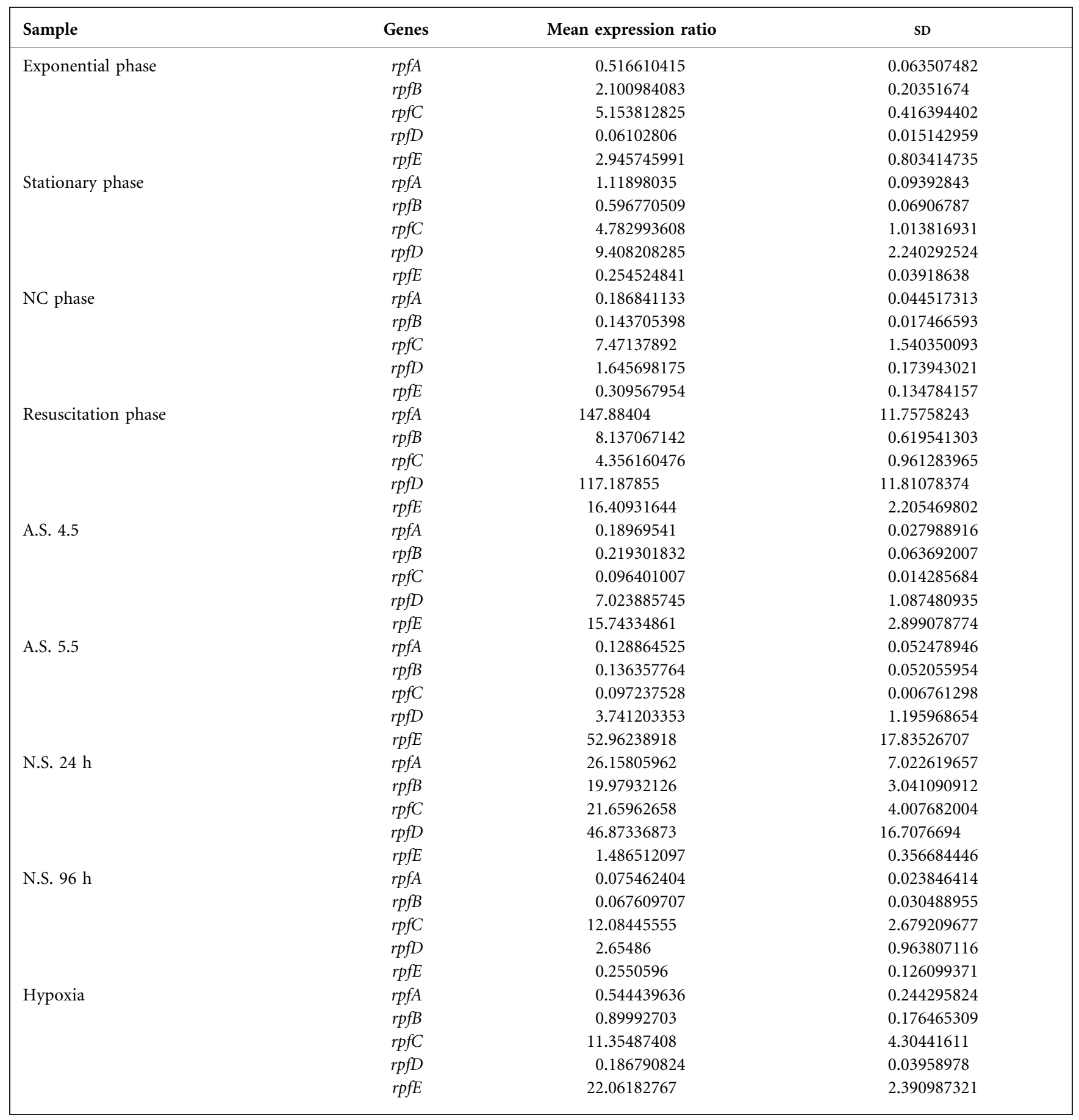

of all five $r p f$ genes was enhanced, with the maximal expression ratio of $r p f A$ and $r p f D$ on the third day of resuscitation (Fig. 1, Table 2). On the 10th day of resuscitation, the relative expression of all five $r p f$ genes was almost identical to that observed in exponential phase (data not shown).

\section{Relative expression of rpfs under stress conditions}

The expression of all five $r p f$-like genes of $M$. tuberculosis $\mathrm{H} 37 \mathrm{Rv}$ was analysed in mildly acidic [acid stress (A.S.) $\mathrm{pH}$ 5.5] and highly acidic (A.S. pH 4.5) conditions compared 


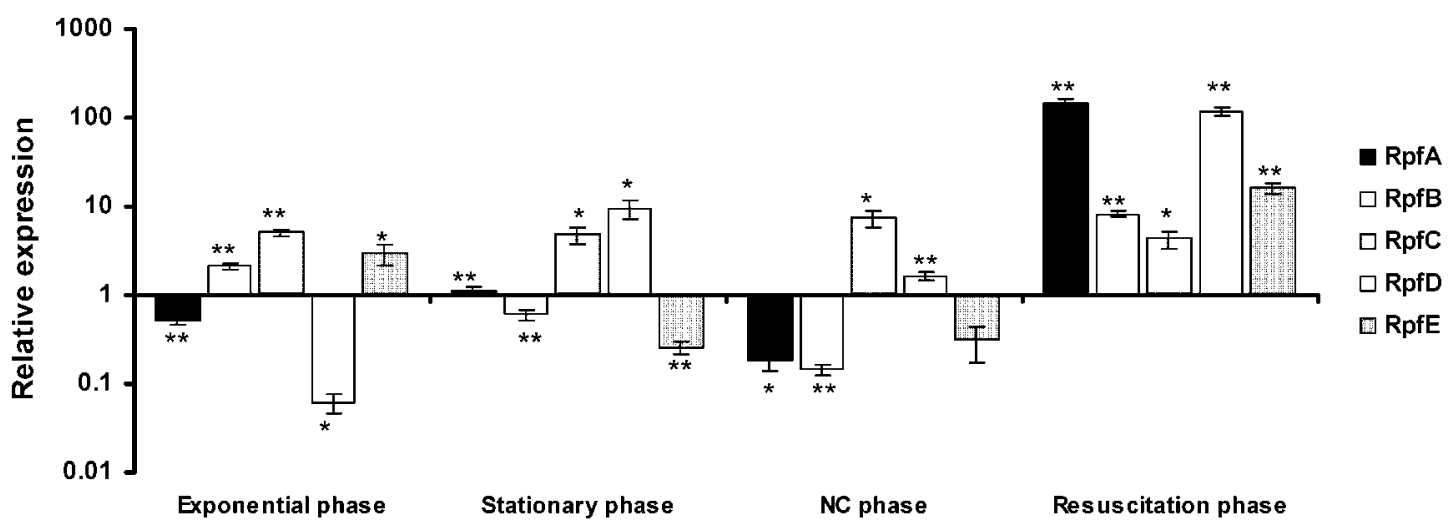

Fig. 1. Relative expression analysis of all five rpf genes (rpfA-E) was followed in exponential, stationary, NC and resuscitation phases by real-time PCR. M. tuberculosis H37Rv was grown in Sauton's medium containing ADC and Tween 80 at $37{ }^{\circ} \mathrm{C}$ without shaking. RNA extraction was done at different growth stages as described in Methods. Early exponential-phase RNA was used as a positive calibrator and 16S rRNA was used as a reference gene for normalization. Data represent mean relative expression values of three independent experiments with SD values (Table 2 ). $P<0.05$ was considered significant $\left(^{*}\right), P<0.01$ was considered highly significant $\left(^{* \star}\right)$ and $P>0.05$ was considered not significant.

with the control grown at normal $\mathrm{pH}$, as described in Methods. RNA of the control culture was used as a positive calibrator for real-time quantitative PCR (qRT-PCR). In mildly acidic ( $\mathrm{pH} 5.5$ ) and highly acidic conditions ( $\mathrm{pH} 4.5$ ), the relative expression of $r p f E$ and $r p f D$ was increased but the expression ratios of $r p f A, r p f B$ and $r p f C$ were decreased. In highly acidic conditions, $r p f E$ had the maximum expression ratio among all $r p f s$ (Fig. 2, Table 2).

The relative expression of all five $r p f$ genes was observed under hypoxia conditions generated as described in Methods. A control culture was used as a positive calibrator for relative expression analysis. After 25 days of culture incubation, complete decolorization of the redox dye methylene blue was observed. At this time point, the $\operatorname{rpfE}$ and $r p f C$ expression ratios were increased, with a maximum expression ratio of $r p f E$. The relative expression of $r p f A, r p f B$ and $r p f D$ was lower compared with the control (Fig. 3, Table 2 ). We analysed the relative expression of all five rpf-like genes during 24 and $96 \mathrm{~h}$ of nutrient starvation (N.S.), using $0 \mathrm{~h} \mathrm{RNA}$ as a positive calibrator and control. It was observed that during $24 \mathrm{~h}$ of nutrient stress, the relative expression of all five $r p f$ genes increased with respect to the control. During prolonged incubation of the culture for $96 \mathrm{~h}, r p f C$ and $r p f D$ had increased expression ratios but the relative expression of $r p f A, r p f B$ and $r p f E$ was decreased (Fig. 4, Table 2).

\section{DISCUSSION}

In this paper, we have analysed the expression of the five $r p$-like genes of $M$. tuberculosis $\mathrm{H} 37 \mathrm{Rv}$ under different

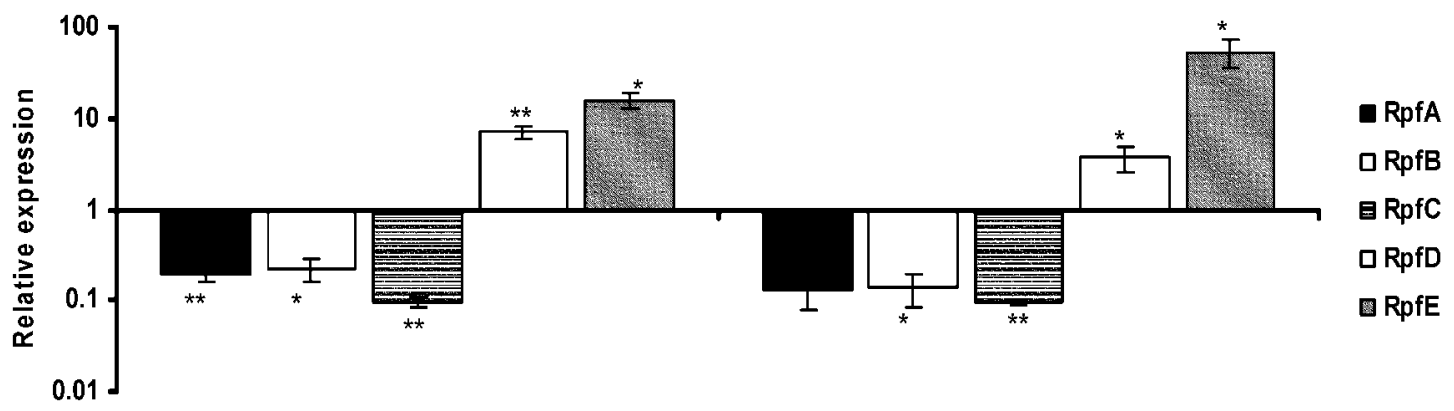

A.S. 4.5

A.S. 5.5

Fig. 2. Relative expression of all five rpf-like genes of M. tuberculosis H37Rv was analysed under mildly acidic ( $\mathrm{pH} 5.5$, A.S. 5.5) and highly acidic (pH 4.5, A.S. 4.5) conditions. Acid stress was generated as described in Methods. RNA isolated from the culture grown in Sauton's medium, pH 7.2, was used as a control or positive calibrator for relative expression analysis. 16S rRNA was used as a reference gene for normalization. Data represent mean relative expression values of three independent experiments with SD values (Table 2 ). $P<0.05$ was considered significant $\left.{ }^{*}\right), P<0.01$ was considered highly significant $\left(^{* *}\right)$ and $P>0.05$ was considered not significant. 


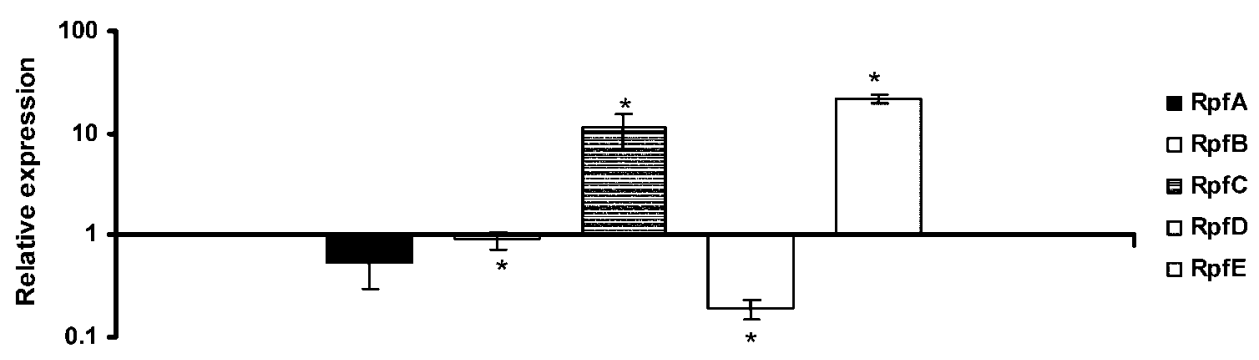

Hypoxia

Fig. 3. Relative expression analysis of all five rpf-like genes of $M$. tuberculosis H37Rv under hypoxia. Hypoxia was generated as described in Methods. RNA isolated from the culture grown aerobically in MB7H9 medium containing ADC and Tween 80 $(0.05 \%$. v/v) was used as a control or positive calibrator for relative expression analysis. 16S rRNA was used as a reference gene for normalization. Data represent mean relative expression values of triplicate experiments with SD values (Table 2). $P<0.05$ was considered significant $\left(^{*}\right), P<0.01$ was considered highly significant $\left(^{\star *}\right)$ and $P>0.05$ was considered not significant.

growth and physiological stress conditions. It was found that all $r p f$ genes were expressed in early resuscitation phase with maximum relative expression for $r p f A$ and $r p f D$. Only $r p f C$ was observed to show consistently increased relative expression during all stages of growth and nutrient starvation. It was also observed that acid stress induced higher relative expression of $r p f D$ and $r p f E$ and hypoxia of $r p f C$ and $r p f E$. The earlier results on expression of the five $r p f(A-E)$ genes in axenic culture from early exponential to stationary phase by semiquantitative $\mathrm{RT}-\mathrm{PCR}$ revealed the expression of all five genes at early time points but differences at later stages of growth (Mukamolova et al., 2002; Downing et al., 2004; Tufariello et al., 2004). The studies showed that $r p f E$ was expressed maximally in the early exponential phase of growth, with expression falling markedly and remaining low throughout (Tufariello et al., 2004). Three of the other $r p f$-like genes, $r p f A r p f B$ and $r p f D$, had higher expression in exponential phase but reduced expression in stationary phase. Only $r p f C$ (rv1884c) was expressed at an undiminished level throughout when compared with early exponential phase (Tufariello et al., 2004). In extended stationary phase (4-month-old culture) of M. tuberculosis, expression of all five $r p f$-like genes can be detected (Tufariello et al., 2004), while no expression is observed in stationary phase and 5-month-old cultures of $M$. bovis BCG (Mukamolova et al., 2002). Differential expression of the five rpf-like genes in $M$. tuberculosis appears to be related to differential regulation and this is supported by functional and mutational analysis of $r p f$ genes.

RpfB has been shown to interact with a putative mycobacterial endopeptidase, designated Rpf-interacting protein A (RipA) (Hett et al., 2007). The two proteins colocalize in the septa of actively dividing cells, suggesting a role for the RipA-RpfB complex in peptidoglycan hydrolysis during cell division. RipA also interacts with RpfE but not with RpfA, RpfC and RpfD, suggesting that these Rpfs may act via a distinct mechanism and/or on a different

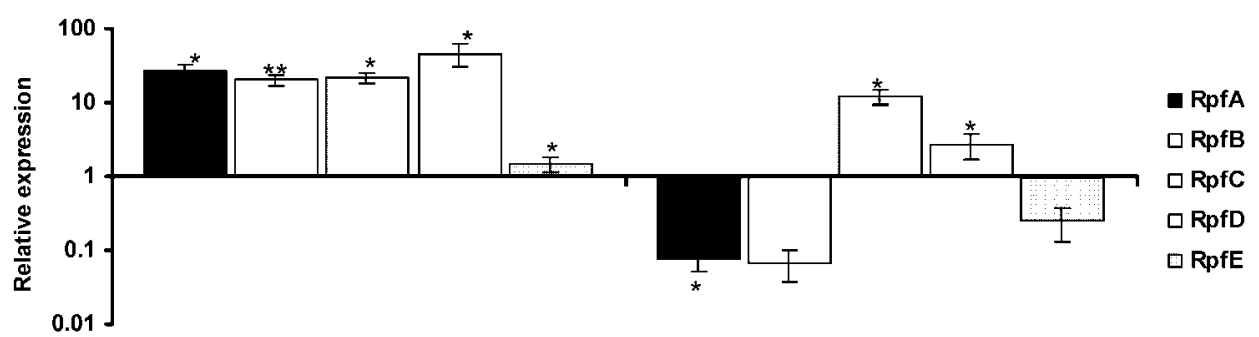

N.S. $24 \mathrm{~h}$

N.S. $96 \mathrm{~h}$

Fig. 4. Relative expression of all five rpf-like genes during 24 and $96 \mathrm{~h}$ of nutrient starvation (N.S.) analysed by real-time $P C R$. Nutrient stress was generated as described in Methods. Cells harvested at $0 \mathrm{~h}$ served as control or positive calibrator for relative expression analysis. 16S rRNA was used as a reference gene for normalization. Data represent mean relative expression values of three independent experiments with SD values (Table 2). $P<0.05$ was considered significant $\left(^{*}\right), P<0.01$ was considered highly significant $\left(^{* *}\right)$ and $P>0.05$ was considered not significant. 
substrate or pathway (Hett et al., 2007, 2008). Similarly, colony formation is delayed in $M$. tuberculosis with mutated $r p f B$, and colonies are much smaller than those of the wild type (Tufariello et al., 2004). The higher expression of $r p f B$ and $r p f E$ observed in exponential phase in our study may thus be related to cell division and growth. RpfC is by far the most abundant resuscitationpromoting factor in M. tuberculosis (Mukamolova et al., 2002; Tufariello et al., 2004). We also found a consistently higher expression ratio of $r p f C$ from exponential to stationary to $\mathrm{NC}$ phase. $r p f C$ appears to be directly regulated by the sigma factor SigD, and in vitro transcription of $r p f C$ has been found to be completely dependent on SigD (Raman et al., 2004). The expression of SigD has been linked to the stringent response, with an increased expression in response to starvation that is partly Rel-dependent (Raman et al., 2004). We also observed enhanced $r p f C$ expression during nutrient starvation (Fig. 3). Hence, $r p f C$ may have a role in stationary-phase adaptation and persistence.

Expression of the $r p f$-like genes during resuscitation of NCC to active growth by $M$. tuberculosis culture supernatant was also examined. Samples were taken on days 3 and 10 of resuscitation. Day 3 was chosen as changes in the composition of the cell population have been reported to occur as early as 3 days after inoculation of NCC in resuscitation medium (Shleeva et al., 2003). The progression of the culture from the NC phase to the resuscitation phase on day 3 resulted in an increase in expression of all five $r p f$ genes. The expression of all the $r p f s$ in early resuscitation phase is anticipated, as it is a recovery phase from the NC state to active growth. The higher expression ratio of all the $r p f$ genes in early resuscitation phase correlates with mutational studies, which clearly suggest that deletion of three or more genes results in impairment of resuscitation from an NC state (Kana et al., 2008; Downing et al., 2005). Deletion of any one of the five $r p f$-like genes does not affect the growth and ability to resuscitate spontaneously from an NC state in vitro (Downing et al., 2005). Similarly single-deletion mutants have been found to be phenotypically similar to wild-type M. tuberculosis $\mathrm{H} 37 \mathrm{Rv}$ in vivo (Downing et al., 2005). However, the multiple mutant strains KDT8 ( $\Delta r p f A$ $\Delta r p f B \Delta r p f C)$ and KDT9 ( $\Delta r p f A \Delta r p f C \Delta r p f D)$, which lack three of the five $r p f$-like genes, are significantly but differentially attenuated in a mouse infection model. These mutants are also unable to resuscitate spontaneously in vitro (Downing et al., 2005). In another study, quadruple mutants $(\triangle r p f A C B D$ and $\triangle r p f A C B E)$ of $M$. tuberculosis were found to be significantly attenuated in a murine infection model, being severely impaired in growth and persistence (Kana et al., 2008). We observed higher relative expression of $r p f A$ and $r p f D$ during early resuscitation. $r p f A$ has been shown to be subject to regulation by the cAMP receptor protein (Rickman et al., 2005), and is reported to be the most potent resuscitationpromoting factor that exhibits activity at femtomolar concentrations (Mukamolova et al., 2002). Among all five Rpf-like proteins of M. tuberculosis, RpfD is considered the most efficient in terms of resuscitation-promoting activity (Cohen-Gonsaud et al., 2005).

Phagosomes containing mycobacteria begin to acidify rapidly after phagocytosis and the $\mathrm{pH}$ drops rapidly to 5.5 or lower. The acidification signal is used by mycobacteria to induce the expression of genes needed to alter phagosomal maturation (Hackam et al., 1998; Oh \& Straubinger, 1996; Sturgill-Koszycki et al., 1994). The induction of $r p f E$ under mildly acidic conditions has been reported previously (Fisher et al., 2002). The loss of $r p f E$ from the triple mutant $\triangle r p f A C B$ has been shown to have pronounced effect on persistence of tubercle bacilli in the lungs of mice (Kana et al., 2008). We observed that in highly acidic conditions the expression ratios of $r p f E$ and $r p f D$ were highest among all $r p f s$, which suggests a role for both $r p f E$ and $r p f D$ in acid-induced stress conditions.

M. tuberculosis is generally regarded as a strictly aerobic bacillus, although it can survive for a long period of time under microaerophilic conditions (Wayne \& Hayes, 1996). An in vitro model to study this persistence state is the Wayne dormancy model, in which the bacteria downregulate their metabolism due to reduced access to oxygen (Wayne \& Hayes, 1996). rpfE has been shown to have a role in persistence, and $r p f C$ is regulated by the transcriptional regulator $\mathrm{SigD}$ required for stationary phase adaptation and persistence (Raman et al., 2004). Our results suggest that both $r p f C$ and $r p f E$ have a role in cell survival during hypoxia-induced persistence, and that $r p f D$ and $r p f E$ have a role in adaptation of $M$. tuberculosis in acid-induced stress conditions, indicating that $r p f E$ is important for the survival of $M$. tuberculosis $\mathrm{H} 37 \mathrm{Rv}$ under stress conditions induced by low oxygen and $\mathrm{pH}$.

M. tuberculosis $\mathrm{H} 37 \mathrm{Rv}$ arrests growth, decreases its respiration and becomes resistant to front-line drugs such as isoniazid, rifampicin and metronidazole under nutrientstarved conditions (Betts et al., 2002). It has been shown that the respiration rate of a nutrient-starved culture declines rapidly over the first $96 \mathrm{~h}$ of starvation (Betts et al., 2002). We have observed that during $96 \mathrm{~h}$ of nutrient stress $r p f C$ and $r p f D$ had higher relative expression, and the expression ratio of $r p f A, r p f B$ and $r p f E$ was decreased. As discussed above, $r p f C$ is under the control of the putative sigma factor SigD, which shows enhanced expression during nutrient starvation (Betts et al., 2002). Starvationinduced expression of sigD is blunted in a relA mutant strain (Dahl et al., 2003), suggesting that $s i g D$ is a part of the RelA regulon required for the stringent response for survival of M. tuberculosis during nutrient starvation. It has been reported that expression of relA was induced under nutrient starvation (Betts et al., 2002), suggesting the increased expression of $s i g D$ together with increased expression of $r p f C$ in nutrient starvation. 


\section{Conclusion}

These studies are consistent with $r p f A$ and $r p f D$ playing important roles in reducing the lag phase during resuscitation, as they have maximum expression ratios in the initial phase of resuscitation (3 days after resuscitation). Only $r p f C$ has a higher expression ratio from exponential phase to the NC state compared with early exponential phase, suggesting that $r p f C$ has a consistently increased relative expression among all rpfs in $M$. tuberculosis. The results suggest that acid stress induces expression of $r p f D$ and $r p f E$ and that hypoxia induces expression of $r p f C$ and $r p f E$. Nutrient starvation induces all the $r p f$ genes in the early phase $(24 \mathrm{~h})$, but later after $96 \mathrm{~h}, r p f C$ and $r p f D$ have higher relative expression. The five $r p f$ genes are differentially expressed under different growth stages and stress conditions, suggesting that they have distinct roles during cell growth and cell survival under stress conditions.

\section{ACKNOWLEDGEMENTS}

We thank the Director for facilities and support. R. K.G. is Senior Research Fellow, Council of Scientific and Industrial Research (CSIR). Statistical analysis was done with the help of Mr Mukesh Srivastava, of the Biometry Division of the Institute. We are grateful to $\mathrm{Mr}$ Brijesh Singh (Roche Diagnostics, India) and Dr Vikas Srivastava for statistical analysis. Support from CSIR and the Department of Biotechnology of the Ministry of Science and Technology is acknowledged. This is Central Drug Research Institute (CDRI) communication number 7914 .

\section{REFERENCES}

Betts, J. C., Lukey, P. T., Robb, L. C., McAdam, R. A. \& Duncan, K. (2002). Evaluation of a nutrient starvation model of Mycobacterium tuberculosis persistence by gene and protein expression profiling. Mol Microbiol 43, 717-731.

Boon, C., Li, R., Qi, R. \& Dick, T. (2001). Proteins of Mycobacterium bovis BCG induced in the Wayne dormancy model. J Bacteriol 183, 2672-2676.

Cohen-Gonsaud, M., Barthe, P., Bagneris, C., Henderson, B., Ward, J., Roumestand, C. \& Keep, N. H. (2005). The structure of a resuscitation-promoting factor domain from Mycobacterium tuberculosis shows homology to lysozymes. Nat Struct Mol Biol 12, 270273.

Dahl, J. L., Kraus, C. N., Boshoff, H. I. M., Doan, B., Foley, K., Avarbock, D., Kaplan, G., Mizrahi, V., Rubin, H. \& Clifton, B. E., III (2003). The role of $\mathrm{Rel}_{\mathrm{Mtb}}$-mediated adaptation to stationary phase in long-term persistence of Mycobacterium tuberculosis in mice. Proc Natl Acad Sci U S A 100, 10026-10031.

Downing, K. J., Betts, J. C., Young, D. I., McAdam, R. A., Kelly, F., Young, M. \& Mizrahi, V. (2004). Global expression profiling of strains harbouring null mutations reveals that the five $r p f$-like genes of Mycobacterium tuberculosis show functional redundancy. Tuberculosis (Edinb) 84, 167-179.

Downing, K. J., Mischenko, V. V., Shleeva, M. O. \& Young, D. I. (2005). Mutants of Mycobacterium tuberculosis lacking three of the five $r p f$-like genes are defective for growth in vivo and for resuscitation in vitro. Infect Immun 73, 3038-3043.
Fisher, M. A., Plikaytis, B. B. \& Shinnick, T. M. (2002). Microarray analysis of the Mycobacterium tuberculosis transcriptional response to the acidic conditions found in phagosomes. J Bacteriol 184, 40254032.

Gedde-Dahl, T. (1952). Tuberculous infection in the light of tuberculin matriculation. Am J Hyg 56, 139-214.

Hackam, D. J., Rotstein, O. D., Zhang, W., Gruenheid, S., Gros, P. \& Grinstein, S. (1998). Host resistance to intracellular infection: mutation of natural resistance-associated macrophage protein 1 (Nramp1) impairs phagosomal acidification. J Exp Med 188, 351364.

Hett, E. C., Chao, M. C., Steyn, A. J., Fortune, S. M., Deng, L. L. \& Rubin, E. J. (2007). A partner for the resuscitation-promoting factors of Mycobacterium tuberculosis. Mol Microbiol 66, 658-668.

Hett, E. C., Chao, M. C., Deng, L. L. \& Rubin, E. J. (2008). A mycobacterial enzyme essential for cell division synergizes with resuscitation-promoting factor. PLoS Pathog 4, e1000001.

Kana, B. D., Gordhan, B. G., Downing, K. J., Sung, N., Vostroktunova, G., Machowski, E. E., Tsenova, L., Young, M., Kaprelyants, A. \& other authors (2008). The resuscitation-promoting factors of Mycobacterium tuberculosis are required for virulence and resuscitation from dormancy but are collectively dispensable for growth in vitro. Mol Microbiol 67, 672-684.

Mukamolova, G. V., Kaprelyants, A. S., Young, D. I., Young, M. \& Kell, D. B. (1998a). A bacterial cytokine. Proc Natl Acad Sci U S A 95, 8916-8921.

Mukamolova, G. V., Yanopolskaya, N. D., Kell, D. B. \& Kaprelyants, A. S. (1998b). On resuscitation from the dormant state of Micrococcus luteus. Antonie Van Leeuwenhoek 73, 237-243.

Mukamolova, G. V., Turapov, O. A., Young, D. I., Kaprelyants, A. S., Kell, D. B., Young, M., Kazarian, K. \& Telkov, M. (2002). A family of autocrine growth factors in Mycobacterium tuberculosis. Mol Microbiol 46, 623-635.

Oh, Y. K. \& Straubinger, R. M. (1996). Intracellular fate of Mycobacterium avium: use of dual-label spectrofluorometry to investigate the influence of bacterial viability and opsonization on phagosomal $\mathrm{pH}$ and phagosome-lysosome interaction. Infect Immun 64, 319-325.

Pfaffl, M. W. (2001). A new mathematical model for relative quantification in real-time RT-PCR. Nucleic Acids Res 29, e45.

Raman, S., Hazra, R., Dascher, C. C. \& Husson, R. N. (2004). Transcription regulation by the Mycobacterium tuberculosis alternative sigma factor SigD and its role in virulence. J Bacteriol 186, 66056616.

Rickman, L., Scott, C., Hunt, D. M., Hutchinson, T., Menéndez, M. C., Whalan, R., Hinds, J., Colston, M. J., Green, J. \& Buxton, R. S. (2005). A member of the cAMP receptor protein family of transcription regulators in Mycobacterium tuberculosis is required for virulence in mice and controls transcription of the $r p f A$ gene coding for a resuscitation promoting factor. Mol Microbiol 56, 12741286.

Salina, E. G., Vostroknutova, G. N., Shleeva, M. O. \& Kapreleyants, A. S. (2006). Cell-cell interaction during the formation and reactivation of "nonculturable" mycobacteria. Microbiology (English translation of Mikrobiologiia) 75, 432-437.

Shleeva, M. O., Bagramyan, K., Telkov, M. V., Mukamolova, G. V., Young, M., Kell, D. B. \& Kaprelyants, A. S. (2002). Formation and resuscitation of "non-culturable" cells of Rhodococcus rhodochrous and Mycobacterium tuberculosis in prolonged stationary phase. Microbiology 148, 1581-1591.

Shleeva, M. O., Mukamolova, G. V., Telkov, M. V., Berezinskaya, T. L., Syroeshkin, A. V., Biketov, S. F. \& Kaprelyants, A. S. (2003). 
Formation of nonculturable cells of Mycobacterium tuberculosis and their resuscitation. Microbiology (English translation of Mikrobiologiia) 72, 64-70.

Sturgill-Koszycki, S., Schlesinger, P. H., Chakraborty, P., Haddix, P. L., Collins, H. L., Fok, A. K., Allen, R. D., Gluck, S. L., Heuser, J. \& Russell, D. G. (1994). Lack of acidification in Mycobacterium phagosomes produced by exclusion of the vesicular proton-ATPase. Science 263, 678-681.

Tufariello, J. M., Jacobs, W. R., Jr \& Chan, J. (2004). Individual Mycobacterium tuberculosis resuscitation-promoting factor homologues are dispensable for growth in vitro and in vivo. Infect Immun 72, 515-526.

Wayne, L. G. \& Hayes, L. G. (1996). An in vitro model for sequential study of shiftdown of Mycobacterium tuberculosis through two stages of nonreplicating persistence. Infect Immun 64, 20622069.

WHO (2010). Tuberculosis. Fact sheet no. 104. (http://www.who.int/ mediacentre/factsheets/fs104/en/index.html)

Edited by: J. Cavet 